\title{
Use of a 595-nm Pulsed-Dye Laser to Treat Post-Procedure Ecchymoses
}

\author{
Sang Ju Lee ${ }^{1}$ \\ Suhyun $\mathrm{Cho}^{2}$ \\ Young Koo Kim ${ }^{1}$ \\ Sung Bin $\mathrm{Cho}^{2,3}$
}

\footnotetext{
${ }^{1}$ Yonsei Star Skin and Laser Clinic, Seoul, Korea

${ }^{2}$ Kangskin Dermatology Clinic, Seoul, Korea

${ }^{3}$ Department of Dermatology and Cutaneous Biology Research Institute, Yonsei University College of Medicine, Seoul, Korea
}

Ecchymoses, caused by extravascular leakage of red blood cells into soft tissue, commonly develop as a result of accidental trauma during cosmetic procedures. Several therapeutic modalities, including topical vitamin $\mathrm{K}$ cream alone or in combination with retinol cream, oral arnica, and topical arnica have been reported to effectively reduce posttraumatic bruising. In addition, treatment of ecchymoses with a 595-nm pulsed-dye laser after facial cosmetic procedures has been shown to be safe and effective. In the current report, we treated a patient with bruising along the abdomen and flanks, which developed after a cryolipolysis procedure. We treated the ecchymotic lesions in our patient with a 595-nm pulsed-dye laser on postoperative day 1 and observed remarkable recovery of the bruising, compared to the untreated control lesions.

\section{Key words}

Pulsed-dye laser; Ecchymosis; Bruising
Received December 10, 2014

Revised December 19, 2014

Accepted December 21, 2014

\section{Correspondence}

Sung Bin Cho

Kangskin Clinic, 1433-38, Sillim-dong, Gwanakgu, Seoul 151-015, Korea

Tel: +82-2-2228-2080

Fax: +82-2-393-9157

E-mail: drsbchođggmail.com

(c) Korean Society for Laser Medicine and Surgery

(@) This is an open access article distributed under the terms of the Creative Commons Attribution NonCommercial License (http://creativecommons.org/ licenses/by-nc/3.0) which permits unrestricted noncommercial use, distribution, and reproduction in any medium, provided the original work is properly cited. 


\section{INTRODUCTION}

Ecchymoses commonly develop as a result of accidental trauma that induces extravascular leakage of red blood cells into soft tissue during various cosmetic procedures. 'Although ecchymoses typically resolve spontaneously without the need for any specific treatment, in cases of severe lesions, social activity can be limited for up to 2-4 weeks. ${ }^{1}$ Meanwhile, several therapeutic modalities, including topical vitamin $\mathrm{K}$ cream alone or in combination with retinol cream, oral arnica, and topical arnica, have been reported to effectively reduce post-traumatic bruising. ${ }^{2-5}$

Additionally, 595-nm pulsed-dye laser therapy for ecchymoses after facial cosmetic procedures has been shown to be safe and effective. 'Laser energy with a wavelength of $595 \mathrm{~nm}$ is also suggested to be preferentially absorbed by extravasated red blood cells that make up the ecchymotic lesions. In this report, we describe the case of a patient with post-cryolipolysis ecchymoses along the abdomen that were effectively treated by $595-\mathrm{nm}$ pulsed-dye laser therapy.

\section{CASE REPORT}

A 43-year-old Korean male patient visited our clinic presenting with localized fat deposits along the abdomen and flanks. He had no pertinent family history or medical history, including essential hypertension, hypercholesterolemia, or bleeding tendency. Despite diet and exercise to reduce body fat, he reported experiencing no remarkable changes therein (Fig. 1A). Thus, after obtaining written informed consent, we performed cryolipolysis on the patient using the CoolSculpting (Zeltiq Inc., Pleasanton, CA, USA) procedure along the abdomen and both flanks. The cryolipolysis procedures were delivered over a treatment duration of 60 minutes with a cooling intensity factor of $42\left(-72.9 \mathrm{~mW} / \mathrm{cm}^{2}\right)$ and $50 \%$ overlap between the treated regions. Immediately after the cryolipolysis, extensive ecchymotic patches developed along the abdomen and both flanks.

One day after the procedure, ecchymotic patches became more distinctive (Fig. 1B). Therefore, treatment with a 595-nm pulsed-dye laser (Vbeam; Candela Corporation, Wayland, MA, USA) was delivered on half of the lesions as a trial. The laser settings comprised a fluence of $7.5 \mathrm{~J} / \mathrm{cm}^{2}$, a $10-\mathrm{mm}$ spot size, a pulse width of 6 milliseconds, and a single pass. An integrated dynamiccooling device was used to protect the epidermis from burns at a setting of 20/20 milliseconds. One (Fig. 1C) and three days (Fig. 1D) after the pulsed-dye laser treatment, the ecchymotic lesions of the treated sites had remarkably improved, compared to those of the untreated sites, without any noticeable side effects.

\section{DISCUSSION}

Body contouring procedures can be performed via invasive or non-invasive methods. Although invasive methods, especially surgical liposuction, can provide more promising clinical outcomes, the risks of side effects associated with anesthesia and invasive procedure are
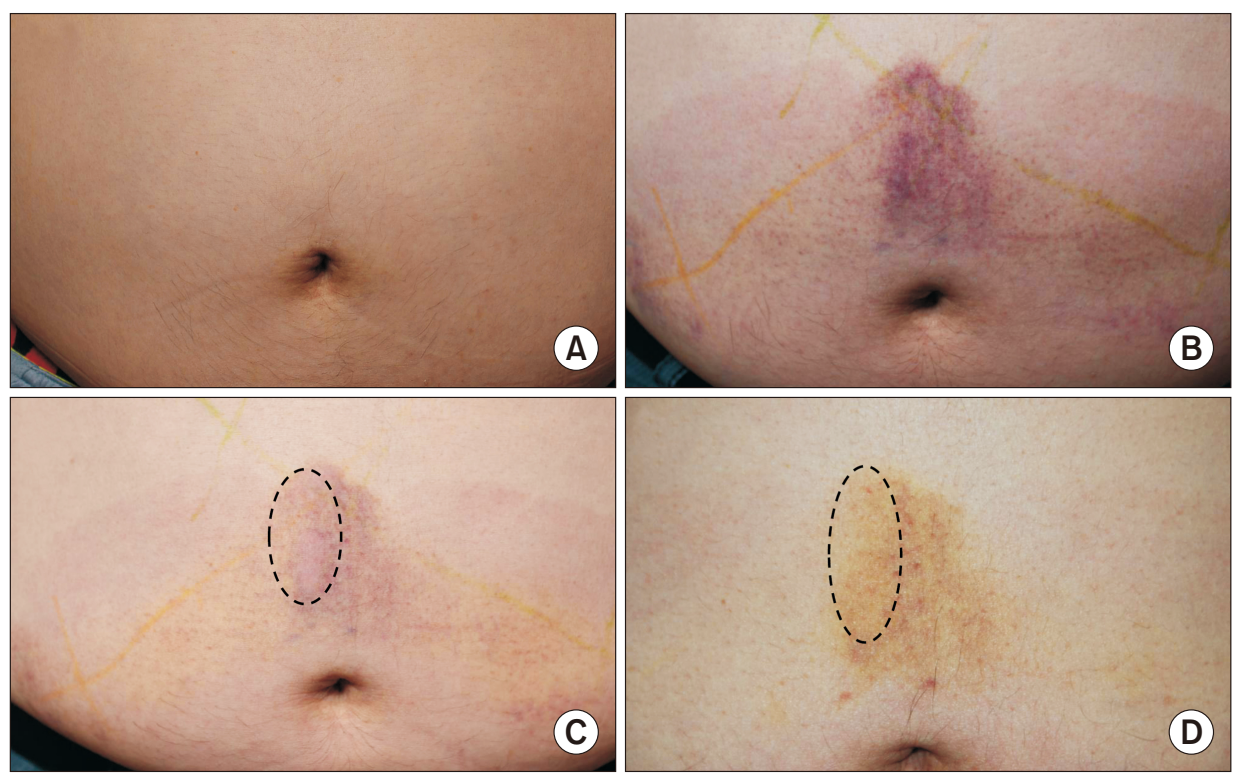

Fig. 1. Clinical photographs showing the abdomen of a 43-year-old Korean male, (A) before and (B) one day after cryolipolysis, as well as (C) one and (D) three days after 595-nm pulsed-dye laser treatment, which was performed one day after cryolipolysis. 
higher and downtime for recovery is longer, compared to non-invasive methods. ${ }^{6-9}$ Nevertheless, non-invasive body contouring methods, including infrared light, low-level laser, or light therapy, high-intensity focused ultrasound, radiofrequency, and cryolipolysis, have been performed with inconsistent clinical results. ${ }^{7-9}$

Cryolipolysis has been utilized to reduce body fat mass by selectively inducing cold panniculitis in targeted tissues, resulting in fat modulation and clearance without damage to surrounding tissues. ${ }^{9,10}$ Compared to other non-invasive methods that induce fat destruction or necrosis, cryolipolysis induces an apoptotic response in adipocytes, which are gradually removed over the following 3 months. Nevertheless, despite its noninvasiveness, cryolipolysis procedures are commonly and transiently associated with side effects of edema, erythema, neuralgia, and bruising.

A previous study reported on the clinical efficacies of $595-\mathrm{nm}$ pulsed-dye laser therapy on 20 patients with ecchymoses, which developed after cosmetic procedures on the face, including thread lift, lipo-contouring or lipotransfer, and cervicofacial rhytidectomy. ${ }^{1}$ In their study, the authors administered pulsed-dye laser treatment with a fluence of $6 \mathrm{~J} / \mathrm{cm}^{2}$ over a $10-\mathrm{mm}$ spot size and pulse duration of 6 milliseconds, with a cryogen spray/delay for 30/20 milliseconds.' The lateral halves of ecchymotic areas were treated with the pulseddye laser on postoperative day 5 or 6 , while the medial half was treated on days 7 to 10 . $^{1}$ Therein, ecchymosis scores improved by $60 \%$ within 2-3 days after the laser treatment, and the authors suggested that the maximal efficacy of this treatment can be obtained when pulseddye laser treatment is performed on postoperative days 5-10. In the present report, we treated a patient with bruising along the abdomen and flanks, which developed after a cryolipolysis procedure. We treated the ecchymotic lesions in our patient with a 595-nm pulsed-dye laser on postoperative day 1 and observed remarkable recovery of the bruising, compared to the untreated control lesions.

Although post-therapeutic ecchymoses or bruising is a transient, relatively mild side effect of cosmetic procedures, severe cases can experience psychological stress, social intimidation, and physical discomfort. Therefore, non-purpuragenic pulsed-dye laser treatment at a wavelength of $595 \mathrm{~nm}$ and low fluence can be used to treat ecchymoses with cosmetically acceptable clinical results.

\section{ACKNOWLEDGMENTS}

We would like to thank Anthony Thomas Milliken, ELS, at Editing Synthase (https://editingsynthase.com) for his help with the editing of this manuscript.

\section{REFERENCES}

1. DeFatta RJ, Krishna S, Williams EF 3rd. Pulsed-dye laser for treating ecchymoses after facial cosmetic procedures. Arch Facial Plast Surg 2009;11:99-103.

2. Leu S, Havey J, White LE, Martin N, Yoo SS, Rademaker AW, et al. Accelerated resolution of laser-induced bruising with topical 20\% arnica: a rater-blinded randomized controlled trial. Br J Dermatol 2010;163:557-63.

3. Shah NS, Lazarus MC, Bugdodel R, Hsia SL, He J, Duncan R, et al. The effects of topical vitamin $\mathrm{K}$ on bruising after laser treatment. J Am Acad Dermatol 2002;47:241-4.

4. Lou WW, Quintana AT, Geronemus RG, Grossman MC. Effects of topical vitamin $\mathrm{K}$ and retinol on laser-induced purpura on nonlesional skin. Dermatol Surg 1999;25:942-4.

5. Seeley BM, Denton AB, Ahn MS, Maas CS. Effect of homeopathic Arnica montana on bruising in face-lifts: results of a randomized, double-blind, placebo-controlled clinical trial. Arch Facial Plast Surg 2006;8:54-9.

6. Shek SY, Chan NP, Chan HH. Non-invasive cryolipolysis for body contouring in Chinese--a first commercial experience. Lasers Surg Med 2012;44:125-30.

7. Nelson AA, Wasserman D, Avram MM. Cryolipolysis for reduction of excess adipose tissue. Semin Cutan Med Surg 2009;28:244-9.

8. Stevens WG, Pietrzak LK, Spring MA. Broad overview of a clinical and commercial experience with CoolSculpting. Aesthet Surg J 2013;33:835-46.

9. Dierickx CC, Mazer JM, Sand M, Koenig S, Arigon V. Safety, tolerance, and patient satisfaction with noninvasive cryolipolysis. Dermatol Surg 2013;39:1209-16.

10. Kim J, Kim DH, Ryu HJ. Clinical effectiveness of non-invasive selective cryolipolysis. J Cosmet Laser Ther 2014;16:209-13. 